\title{
ARTÍCULO
}

\section{EL ABORTO Y LOS LÍMITES DE LA AUTONOMÍA}

\author{
Jorge Fábrega \\ Universidad Adolfo Ibáñez
}

\begin{abstract}
Resumen: ¿Basándose en el principio de autonomía, ¿debe concluirse que el aborto es éticamente justificable? La aplicación del principio de autonomía al problema del aborto obliga a la justificación ética de prácticas sobre la vida de los recién nacidos que, hoy por hoy, parecen ser aberrantes. Por lo tanto, en este caso, una sociedad de individuos autónomos consideraría razonable limitar los alcances del principio de autonomía recurriendo a otras fuentes de valor. Como resultado el dilema ético del aborto no puede ser resuelto sobre la base de dicho principio y los denominados derechos abortivos, fundados en él, deben ser reevaluados.

Palabras clave: aborto, autonomía, razón pública.

Recibido: mayo 2012; aceptado: junio 2012.
\end{abstract}

Jorge Alberto Fábrega Lacoa. Doctor en Políticas Públicas, Universidad de Chicago. Economista y Sociólogo, Pontificia Universidad Católica de Chile. Profesor Asistente, Escuela de Gobierno, de la Universidad Adolfo Ibáñez. Dirección electrónica: jorge.fabrega@uai.cl.

* Agradezco muy especialmente a Aldo Mascareño y Gonzalo Bustamante por sus comentarios al trabajo, así como también agradezco los comentarios recibidos de los participantes en el foro "Aborto en Chile ¿Por qué sí, por qué no?" realizado en la Universidad Adolfo Ibáñez el 25 de abril del 2012, y a dos árbitros anónimos de Estudios Públicos. 


\begin{abstract}
ABORTION AND THE LIMITS OF AUTONOMY
Abstract: Based on the principle of autonomy, should we conclude that abortion is ethically justified? Applying the principle of autonomy on the issue of abortion forces the justification of some aberrant consequences affecting the lives of newborns. Therefore, in this case, a society of autonomous individuals would consider reasonable to limit the scope of the principle of autonomy resting on other sources of moral value. The result is that the ethical dilemma of abortion cannot be solved solely on the principle of autonomy and the moral status of the so called abortion rights, based on such a principle, must be revisited.
\end{abstract}

Keywords: abortion, autonomy, public reason.

Received: May 2012; accepted: June 2012.

\title{
Aborto: Un debate abierto
}

$\mathrm{L}$

a autonomía, la capacidad de autodeterminación, es una regla fundamental de nuestra vida en común. Sobre ella se fundan valores básicos que hoy son ampliamente compartidos, tales como la existencia de derechos humanos universales. Por lo anterior, es comprensible que el foco de la discusión sobre derechos abortivos se centre sobre la razonabilidad o no razonabilidad de restringir la autonomía de la mujer embarazada. En una primera reflexión, en virtud del principio de autonomía, no debería existir un dilema ético respecto al aborto: la mujer, en cuanto ser dotado de autonomía, posee derechos - entre otros - a disponer de su cuerpo. En cambio, un embrión y un feto no son seres autónomos y, por tal motivo, no serían sujetos de derechos. En consecuencia, la sociedad tendría la obligación de respetar las decisiones soberanas que la mujer embarazada realice sobre la base de dichos derechos. Fin del dilema ético ${ }^{1}$.

${ }^{1}$ Por ejemplo, Rothbard (1998, p. 98) sostiene: "El terreno apropiado para hablar del aborto es sobre el derecho absoluto de todo humano sobre tu propio cuerpo. Esto implica que toda mujer tiene derecho absoluto sobre su cuerpo, que ella tiene absoluto dominio sobre su cuerpo y todo lo que contenga. Esto incluye al feto [...] si la madre decide que no desea más al feto allí, entonces, el feto se convierte en un parásito que invade su cuerpo, y la madre tiene el perfecto derecho de expulsar a ese invasor de su dominio" (traducción propia). 
Entonces, ¿existe alguna justificación ética para limitar los derechos abortivos? Como indica Rawls (1993), un postulado normativo es justo y puede ser concebido como parte de la razón pública si quienes se rigen por él lo entienden como legítimo. Por eso, en el contexto de una sociedad que reconozca la libertad de pensamiento, de existir una justificación, ésta no puede fundarse en creencias religiosas porque los individuos que no compartan dichos credos están impedidos de aprehender las normas que de ella se derivan. Por tanto, en esos casos, su sometimiento a la norma sólo puede sustentarse mediante coacción. Tal imposición legal sobre ellos sería injusta y, por ende, ilegítima. En tal sentido, el argumento de la autonomía para ofrecer bases normativas a la validez del aborto es impecable: nadie obligaría a una mujer que no quiera abortar que lo haga, pero tampoco obligaría a otra mujer a renunciar a su derecho a disponer de su cuerpo y abortar si ello es lo que desea. No obstante, la argumentación sobre la base de creencias religiosas no es ni la única ni la principal objeción que puede hacerse sobre derechos abortivos. En este artículo deseo documentar que es el propio concepto de autonomía, por sus implicancias, el que motivaría a individuos autónomos a comprometer límites a la aplicabilidad del concepto $\mathrm{y}$, por ende, limitar tales derechos.

Para evaluar la pertinencia de un principio normativo como justificación de reglas vinculantes, tal principio debe ser analizado en todas sus consecuencias. Ello no es una posibilidad más entre muchas; al contrario, se trata de un ejercicio necesario para deducir (y no imponer) ese criterio como legítimo. Dicho ejercicio tiene dos etapas: primero, se debe analizar las consecuencias lógicas que se derivan de la aplicación del principio en cuestión en diversos escenarios relevantes; $y$, posteriormente, se debe evaluar su razonabilidad, vale decir, la posibilidad de que sea aceptable como principio rector por quienes se han de guiar por él, es decir, como parte de la razón pública.

Ese ejercicio aplicado sobre el principio de autonomía genera algunas implicancias con escasas posibilidades de calificar como parte de la razón pública. Específicamente, si la despenalización del aborto se justifica sobre el principio de autonomía, lo mismo ha de concluirse del infanticidio de un neonato y de todo infante que no ha alcanzado el desarrollo suficiente para que su autonomía sea eviden- 
te ${ }^{2}$. Esta incómoda conclusión es conocida entre los defensores de los derechos abortivos, al menos desde Tooley (1972).

El resto del artículo es organizado del siguiente modo. En la sección 1 se explica la consistencia ética del infanticidio con el principio de autonomía. Debido a lo inconveniente que resulta tal conclusión para las posturas a favor de los derechos abortivos, varias argumentaciones han tratado de establecerse para delimitar los alcances del argumento de modo tal que se justifique el aborto, pero no el infanticidio. Algunas de las principales argumentaciones que en tal sentido han sido propuestas son evaluadas en la sección 2 concluyéndose que todas, sin distinción, han fracasado. En la sección 3 se reflexiona sobre las razones que impiden al concepto de autonomía ser un criterio suficiente para dirimir el dilema ético del aborto y cómo, a partir de tal reflexión, individuos autónomos redescubren el valor moral de otras posturas que, en un primer momento, habrían sido descartadas como fuentes de derechos, abriendo la posibilidad para la justificación ética de la limitación a los derechos abortivos.

\section{La autonomía y su invitado indeseado: El infanticidio}

La consistencia del infanticidio con el concepto de autonomía posee una larga tradición. En forma paralela, Michael Tooley (1972, 1974) y Mary Ann Warren (1973) han argumentado que las posturas antiabortistas cometen un error argumentativo al confundir el concepto de "persona" (ente autónomo) con el concepto de "ser humano". Warren resume el argumento contrario al aborto en un silogismo en tres pasos: (1) es errado matar seres humanos inocentes, y (2) los fetos son seres humanos inocentes, entonces (3) es errado matar fetos (véase, Warren 1973:4). El error de dicho argumento antiabortista radicaría en que el uso del término "seres humanos" en la primera frase difiere de su uso en la segunda frase. Mientras en la primera conlleva un juicio moral

${ }^{2}$ Por infanticidio no debe entenderse sólo la provocación de la muerte de un infante motivada por pasiones. Bajo el mismo término caben una multiplicidad de acciones guiadas por razones, tales como la eutanasia infantil de un neonato con escasas posibilidades de sobrevida, la decisión de acabar con un neonato en virtud de la carga económica de su incorporación al núcleo familiar y la posibilidad de la producción instrumental de humanos como recurso para fines médicos (para generar oferta de órganos y otras partes del cuerpo). 
(es errado matar personas), en la segunda se trata de una descripción (los fetos son seres humanos). El error de la postura contraria al aborto radicaría en confundir ambas dimensiones otorgando valor moral a una descripción biológica. Dicho de otro modo, no puede deducirse que un individuo tenga derechos por ser parte de una especie, en este caso, la humana.

La pregunta moral relevante es ¿cuándo un ser humano —o cualquier otro ser- adquiere el status moral de sujeto de derechos, entre ellos, el derecho a la vida? ¿Cuáles son las propiedades que debe tener un ente para ser considerado una persona y, gracias a ello, sujeto de derechos? A juicio de Tooley la respuesta a esa pregunta es que "un organismo tiene un serio derecho a la vida sólo si posee la idea de 'yo' como sujeto continuo de experiencias y otros estados mentales, y cree que es en sí mismo una entidad continua" (Tooley 1974:78). Warren, por su parte, ofrece un listado de criterios que han de cumplirse para considerar a una entidad una persona autónoma. Éstos son: poseer conciencia, una capacidad desarrollada de razonamiento, actividad independiente (es decir, motivada internamente y no a causa de control externo o genético), capacidad de comunicarse y la presencia de algún concepto de sí mismo (véase Warren 1973:5). Tales requisitos son precisamente los que quedan capturados en el concepto de autonomía.

A partir del principio de autonomía, Tooley infiere: "tener derecho a la vida presupone que se es capaz de continuar existiendo como sujeto de experiencias y otros estados mentales. Esto, a su vez, presupone que se tiene el concepto de tal entidad continua y que se cree que uno es esa entidad. De modo que una entidad que carece de esa conciencia no tiene derecho a la vida" (Tooley 1974:84). Y concluye: "Sería natural preguntar, llegados a este punto, si la satisfacción de esta exigencia es no sólo necesaria sino suficiente para asegurar que una cosa tiene derecho a la vida. Me siento inclinado a decir que sí, sin embargo, la cuestión no es urgente en este contexto, ya que, en la medida que la exigencia es realmente necesaria, ya tenemos la base para una defensa adecuada del aborto y el infanticidio" (Tooley 1974:84). Warren agrega que en el caso de neonatos con severas anomalías físicas cuyas vidas serían probablemente cortas o muy miserables no sería moralmente cuestionable que se termine con el tratamiento, permitiendo al infante una muerte sin sufrimiento, agregando que neonatos en estado terminal "no pueden 
tomar esa decisión por ellos mismos, y así, corresponde que personas responsables tomen la decisión por ellos" (traducción propia).

La reducción del dolor innecesario del neonato con escasas posibilidades de sobrevivencia mediante la eutanasia ha sido planteada también por otros autores. Por ejemplo, Peter Singer (2009) ha sostenido que no hay una persona autónoma en un infante con una discapacidad severa (por ejemplo, en el caso que no posea cerebro) y, por tanto, el infanticidio (o si se prefiere, la eutanasia) en esos casos es éticamente justificable. No obstante, la consideración misericordiosa hacia el infante es un juicio valorativo del que comete o evalúa la acción, pero si tal infante no es un ser autónomo, no es un juicio que aquél pueda comprender o evaluar por sí mismo. Por tanto, limitar el infanticidio a casos de infantes con patologías severas es una restricción sobre las posibilidades del infanticidio que no está debidamente justificada. Por un lado, se indica que el hecho de pertenecer a la especie humana no es fuente que dé derecho a la vida (pues ella se entiende como derecho sólo en un individuo que puede atribuirle algún valor a su propia existencia $\mathrm{y}$, a partir de eso, dar libre curso a su auto-determinación); pero, por otro lado a su capacidad de sentir dolor se le asigna valor moral pese a que el neonato no es un ser autónomo.

Como tal restricción no parece justificable bajo el principio de autonomía, Giubilini y Minerva (2012) han expandido el argumento en sus implicancias lógicas. A juicio de los autores, justificar el infanticidio en base a los beneficios que ello trae para el neonato equivoca el trasfondo desde el cual se realiza el juicio ético. El foco no es aliviar el dolor innecesario del neonato, sino el bienestar de los seres autónomos (madre, familia) que han de hacerse cargo de aquél. En consecuencia, el principio no es la permisibilidad ética de la eutanasia en esos casos, sino el bienestar, esencialmente, de la madre. Por tal motivo, sugieren que es errado hablar de infanticidio (equiparando el status del neonato con el de un infante) y que sería más apropiado hablar de "aborto después del nacimiento" (after-birth abortion) debido a que la condición moral del neonato es equivalente a la del feto. Por ende, concluyen que no sólo es moralmente justificable el infanticidio del recién nacido con serias discapacidades, sino de igual modo lo es el de un recién nacido sano. Para los autores, el infanticidio de un neonato sería éticamente permisible en todas las circunstancias en las que el aborto también lo es. Entre tales circunstancias se incluyen los casos donde el neonato tenga "el poten- 
cial de tener una vida al menos aceptable, pero donde el bienestar de la familia esté en riesgo" (traducción propia, Giubilini y Minerva 2012:2).

En suma, si el principio de autonomía es el fundamento normativo sobre el cual basar el justo proceder y, además, cualquier consideración adicional debe someterse lexicográficamente a no contradecir tal principio, entonces, todo ser no autónomo carece de derechos (o bien, de tenerlos, éstos no pueden ser ejercidos a costa de los derechos de un ser que sí es autónomo) y, como consecuencia, no sólo el aborto, sino también el infanticidio de un neonato (al menos por algunas semanas o meses) serían éticamente incuestionables. La justificación ética del infanticidio es una conclusión necesaria de imponer el principio de autonomía por sobre cualquier otro principio en estas materias: si el aborto es justificable porque no se está acabando con la vida de un ser autónomo, el mismo criterio es válido para el neonato cuya autonomía aún está “en gestación”. La conclusión no sólo es consistente sino también polémica. Sin embargo, una persona que funda su argumentación en estos temas sobre el principio de autonomía (y sólo sobre ese principio o, al menos, sobre la priorización de éste frente a todo otro principio) no puede estar en desacuerdo con estas ideas si pretende ser consistente en su análisis.

Como indiqué en el tercer párrafo de este artículo, el escrutinio de un criterio normativo para saber si puede formar parte de la razón pública requiere evaluar su consistencia, pero también su razonabilidad. Si bien el infanticidio ha sido practicado en la historia humana (véase Singer 2009), las sociedades actuales donde la legitimidad del principio de autonomía se ha establecido, parecen escandalizarse ante la posibilidad de considerar el infanticidio como algo legítimo. Tal reacción no necesariamente obedece a la persistencia de visiones asociadas a alguna doctrina religiosa particular que postule como axioma de sus creencias el valor sagrado de la vida del infante y que, por lo tanto, se presente a sí misma como una resistencia a la expansión de la idea moderna de autonomía. Al respecto son particularmente ilustrativos los estudios de la desaparición de los mercados de seguros de vida para infantes realizado por Vivian Zelizer y de las decisiones racionales de las parejas respecto al número de hijos que desean tener, avanzado por Gary Becker ${ }^{3}$.

3 En contraposición a lo expuesto aquí, Singer (2009) postula que "nuestra actual protección absoluta de la vida de los niños es una actitud típicamente cristiana más que un valor ético universal" (Singer 2009:176). 
A finales del siglo XIX, un menor de un año de edad podía ser asegurado en los Estados Unidos por un pago semanal de 3 centavos que, en caso de muerte, reportarían a sus padres la suma de $\$ 10$ dólares de la época. En dicho contexto, el infante poseía un valor instrumental, intercambiable y cuantificable. Su vida tenía precio. Tales formas de intercambio económico sobre la base de la vida o sobrevida de los infantes desaparecieron durante el siglo XX. Mediante el análisis de dicha desaparición, Zelizer (1985) muestra convincentemente cómo ello obedeció a una paulatina desmonetización del valor de la vida de los infantes convirtiéndolos en "objetos" de valor inconmensurable (the priceless child). Zelizer concluye su estudio con esta aclaradora afirmación: "Este análisis de la historia de los seguros para niños en los Estados Unidos sirve como un indicador de grandes cambios en el valor de las vidas de los niños, especialmente el surgimiento de una infancia económicamente sin valor pero emocionalmente invaluable [...] un cambio en los valores redefinieron normativamente la concepción de la infancia en América [...] un nuevo 'sagrado' infante tuvo que ser sacado del mercado, inútil pero adorable" (Zelizer 1985:1052) .

Desde una perspectiva diferente, la teoría del capital humano ofrece un antecedente complementario (véase Becker 1993); durante el siglo XX, por un lado, las tasas de mortalidad infantil se redujeron debido a los avances médicos $\mathrm{y}$, por otro lado, la creciente demanda por capital humano redujo el valor económico del trabajo infantil y aumentó el de las mujeres (impulsando su ingreso al mercado laboral). En el nuevo contexto, las familias debían elegir entre, por un lado, tener más hijos a los que podrían ofrecerles menores perspectivas de formación en capital humano y, por otro lado, tener menos hijos con mejor formación para ellos y más posibilidades para los adultos de la familia para participar del mercado laboral. El resultado de esa disyuntiva inclinó la balan-

${ }^{4}$ La cita completa del párrafo es la siguiente: "This analysis of the history of children's insurance in the United States serves as an indicator of broader changes in the value of children's lives, specifically the emergence of the economically worhless but emotionally priceless child. The expulsion of children from the market at the turn of the past century, although clearly shaped by materialist concerns, ultimately exceeded a mere economic calculus. A shift in values redefined normative conceptions of childhood in America. As the emotional and moral uniqueness of children was stressed, pragmatic pecuniary equations of their value became increasingly inadequate. The new 'sacred child han to be kept off the market, useless but loving” (Zelizer 1985:1052). 
za hacia una reducción de la fecundidad y una mayor inversión familiar en cada infante en cuanto individuo único e irremplazable ("calidad versus cantidad").

Los ejemplos anteriores dan cuenta de procesos socioeconómicos que seguirán acentuándose en el futuro, que pueden explicar el surgimiento histórico de la actual valoración que se le otorga a la vida del infante sobre cuya pérdida (por fallecimiento) sus padres no manifiestan disposición a pagar por un seguro compensatorio. En ambos casos, la valoración de la vida del infante no se fundamenta en doctrinas religiosas, sino en el valor que la existencia del infante posee para otros individuos que sí son autónomos. Es decir, los mismos individuos autónomos contemporáneos que, por un lado, considerarían legítimo rechazar la fundamentación religiosa para imponer límites a la autonomía, están abiertos a imponer tales restricciones al actuar de terceros sobre la vida de un individuo no autónomo, como es el recién nacido. De hecho, tales restricciones se han ido implementando con el transcurso de los años en la forma de sanciones tanto legales como sociales a quienes comenten maltrato, abuso y/o provocan la muerte de un infante.

Resumiendo, la argumentación hasta este punto presenta dos ideas que colisionan entre sí. Por un lado, la aceptación del principio de autonomía como el único fundamento sobre el cual emitir un juicio ético respecto a la legitimidad del aborto tiene como consecuencia necesaria la validación del infanticidio. Por otro lado, en las sociedades contemporáneas se está profundizando la creencia en un valor sustantivo que individuos racionales y autónomos reconocen en el infante y que conlleva, entre otras implicancias, la condena del infanticidio.

En consecuencia, la fundamentación ética del aborto en el principio de autonomía, y sólo sobre tal principio, corre el riesgo de ser ilegítima y no constituirse en terreno apropiado sobre el cual fundar la razón pública sobre la materia.

Esa posibilidad es anticipada por Warren (1973), quien se apura en aclarar: "Estoy consciente que estas conclusiones [...] son sentidas por otras personas como moralmente monstruosas, y algunas personas podrían incluso preferir abandonar su apoyo previo a los derechos femeninos a abortar antes que aceptar una teoría que conduce a tales conclusiones sobre el infanticidio. Pero lo que estos hechos muestran es que no es posible entender el aborto como un tema moral aislado; para comprender plenamente el status moral del aborto debemos también 
reconsiderar otros temas morales, temas no sólo sobre infanticidio y eutanasia, sino también sobre los derechos morales de las mujeres y de animales no humanos" (traducción propia, Warren 1973:9).

Cuando las implicancias de un postulado son o pueden ser consideradas como inaceptables, cabe preguntarse si restricciones sobre el criterio pueden resolver el problema. En particular, corresponde indagar si existen limitaciones consistentes con la supremacía del principio de autonomía (por sobre cualquier otro principio) que al ser consideradas harían posible distinguir el juicio ético sobre aborto respecto al juicio ético sorbe el infanticidio. En la siguiente sección se evalúan algunos argumentos que han sido propuestos como base para hacer esa distinción. La conclusión es pesimista: la búsqueda de matices es infructuosa.

\section{Argumentos (incompletos) para justificar el aborto, pero no el infanticidio}

El status moral del feto ha recibido tres tipos de tratamientos distintos entre los proponentes del principio de autonomía. Cada una de estas líneas argumentativas genera implicancias sobre la distinción entre infanticidio y aborto. Primero, se ha propuesto que el aborto es éticamente justificado incluso si se reconoce un status moral del feto, por ejemplo, incluso si se reconoce que posee derecho a la vida. Segundo, se ha propuesto que el nacimiento es un hecho moral relevante. Finalmente, se ha propuesto que el status moral del feto es incierto y que el juicio moral debe fundarse en tal incertidumbre. Las trataremos sucesivamente.

\subsection{Aborto cuando se asume que el feto tiene derechos}

Si se reconoce que el feto tiene derechos, como sostiene la postura antiabortista, ¿significa ello que el aborto es éticamente inaceptable? En la década de 1970, Judith Jarvis Thomson dio una respuesta negativa a esta pregunta. En un famoso ejercicio argumentativo Thomson sugiere imaginar una situación en la que un consagrado violinista posee una enfermedad renal mortal cuya única salvación es que se le conecte al cuerpo de una persona sana para purificar su sangre. Dadas las circunstancias, los seguidores del violinista lo han secuestrado durante la 
noche a usted y lo han conectado al enfermo sin su consentimiento. Al despertar, junto a la cama está el doctor quien le dice: "El violinista está ahora conectado a usted. Desconectarlo sería matarlo. De todos modos, no se preocupe, sólo durará nueve meses. Para entonces se habrá recuperado de su enfermedad, y podrá ser desconectado de usted sin ningún peligro" (Thomson 1974:11).

En tal circunstancia, pregunta Thomson, ¿es éticamente justificado que usted desconecte los cables que lo unen al violinista y se vaya? Nótese que en este ejemplo nadie pone en duda la condición de ser autónomo que ostenta el violinista y, en cuanto tal, tiene derechos, entre ellos el derecho a la vida. Por ende, si la respuesta a la pregunta de Thomson es que se justifica éticamente que usted se libere de una situación en la que no ha querido estar, entonces las razones no se fundan en la negación del status moral del afectado. Thomson sugiere que la respuesta es que considerando que usted es un ser autónomo y, como tal, posee derechos sobre su cuerpo, nada justifica que contra su voluntad se le impida ejercer esos derechos. En consecuencia, sería éticamente justificado que usted se levante y se vaya, aun a sabiendas que aquello significará la muerte del violinista.

Si el violinista es un buen símil del feto y usted de la mujer embarazada, la conclusión es que aun cuando se reconozca que un feto tiene derecho a la vida, ello no significa que una mujer esté obligada al embarazo si no es lo que desea. De este modo, sugiere Thomson, los embarazos producto de una violación y, en general, todo embarazo no deseado deberían poder ser terminados. Dicho de otro modo, el reconocimiento del derecho a la vida del feto no sería una justificación válida para imponer restricciones sobre derechos abortivos. Por otro lado, el argumento permite descartar el infanticidio precisamente en virtud del derecho a la vida. Es decir, basándonos en el argumento de Thompson podríamos concluir que el reconocimiento del derecho a la vida del feto garantiza la protección de la vida tanto del feto como del recién nacido; con la única limitación sobre el primero en aquellas situaciones en que el embarazo no es deseado.

En el debate en Chile sobre el aborto, Bascuñán (2004) ha sugerido esta línea argumentativa para justificar tanto ética como jurídicamente los derechos abortivos. Sostiene Bascuñán: "El fundamento de justicia política de la prohibición del aborto consentido no se deduce de la afirmación de la prohibición de dar muerte a un ser humano. La pro- 
hibición de matar es un deber de no causar un daño a otro. Sólo impone al destinatario una restricción de su libertad general de acción. La prohibición del aborto consentido implica para la mujer un deber de tolerar la afectación de intereses propios en beneficio de otros. No sólo se impone una restricción de su libertad de acción, sino que le exige una contribución al bienestar del feto que desde el punto de vista de la justicia política es propia de un deber de solidaridad" (Bascuñán 2004:167). El argumento es persuasivo: la restricción de mis acciones sobre otros no pueden suponer obligaciones no consentidas de contribuir positivamente a su bienestar. Sobre la base del principio de autonomía sólo queda concluir que tales restricciones son éticamente injustificadas.

No obstante, el argumento es errado. Se entenderá mejor el error si relajamos un supuesto que hace Thompson en la formulación del problema. Thompson sostiene que el violinista debe ser conectado a una persona específica porque es la única que tiene un tipo de sangre compatible con el músico. Supongamos que eso no es así y el violinista sólo requiere ser conectado a otra persona. En tal caso, sus posibilidades de vida están asociadas a estar conectado al cuerpo de otro ser humano, pero no necesariamente a un cuerpo específico. Como consecuencia, el violinista poseería alternativas para continuar su vida (siendo conectado a otro individuo que sí acepte estar en esa condición por nueve meses) y es posible separar su derecho a la vida, del derecho de toda persona a disponer de su propio cuerpo. Éste es el elemento medular en la argumentación de Thompson: el derecho a la vida de un individuo puede ser sostenido sin que ello signifique imponer restricciones en el derecho de otro individuo a disponer del propio cuerpo. Desafortunadamente, tal separación no es aplicable aquí. El feto no tiene la opción de otro cuerpo (como no la tiene el violinista en el ejemplo original de Thompson). En rigor, dado nuestro estado actual de avance tecnológico, no existe otra "tecnología" para que un ser humano nazca que no sea dentro de un útero y siempre el mismo útero. Mientras esa restricción práctica exista, el caso del aborto es uno en el que no es posible separar ambas fuentes de derecho: el reconocimiento de una necesariamente implica la negación de la otra.

Por ejemplo, si la separabilidad se incluye en el ejemplo del violinista, el escenario propuesto por Thomson sería distinto. Frente a la dramaticidad del secuestro y la posterior conexión involuntaria al violinista, se impone un escenario menos dramático que podría plantearse así: un 
grupo debe decidir si hace algún esfuerzo por salvar la vida del violinista y debe preguntarse si alguien voluntariamente está dispuesto a ser conectado a él durante nueve meses ¿Puede el individuo que solidariamente se ha ofrecido a conectar su cuerpo al violinista desconectarse antes de tiempo? Si tal posibilidad procede o no dependerá del acuerdo voluntario que las partes involucradas establezcan y las contingencias que para tal efecto consideren. Todo ello, deja de ser un dilema ético relevante y se transforma en un problema de diseño contractual. Si el grupo, en cambio, lo secuestra a usted eso será ilegítimo y deberá compensarlo por su acción. Realizado aquél acto, usted podrá desconectarse y ellos deberán buscar otro cuerpo al cual conectar al músico que desfallece.

Lo distintivo del caso del violinista no es que pueda morir si usted se desconecta (ello de igual modo hubiese sucedido si no se le hubiera conectado), lo particular tiene relación con la situación no buscada en la que se encuentra usted al estar conectado contra su voluntad al músico. Por ello, como la fuente de valor es la autonomía de las personas, si se reconoce o no el derecho a la vida del violinista es irrelevante (por la forma en que es construido el ejercicio reflexivo). En suma, si se prioriza el derecho del ser autónomo (la madre), el derecho a la vida del feto no recibe en el ejercicio, por construcción, el mismo status moral. Dada la construcción del ejercicio teórico no debe extrañar entonces que la conclusión sea una afirmación de los derechos abortivos.

En suma, como el feto no tiene opciones, cuando se asume que es poseedor del derecho de vivir, entonces necesariamente se deduce una obligación de solidaridad de la mujer en cuyo vientre se está gestando $\mathrm{y}$, en consecuencia, una limitación a los derechos de ésta sobre su propio cuerpo. Y, en términos generales, una limitación al principio de autonomía. En consecuencia, si se intenta reconciliar el principio de autonomía con la prohibición del infanticidio sobre la base del derecho a la vida del feto, la reflexión nos debería llevar a concluir que se debe prohibir el aborto como regla general. Conclusión que claramente contradice la premisa inicial.

\subsection{Los fetos y neonatos son moralmente distintos: Varios argumentos}

Una línea argumentativa distinta puede considerar moralmente aceptable el aborto y al mismo tiempo rechazar el infanticidio sin suponer que el feto posee derecho a la vida. Una alternativa es sugerir que 
el recién nacido posee potencial de autonomía ya que, fuera del vientre materno, puede desarrollarse de forma independiente. El argumento parece razonable porque, por un lado, abre espacio para que se justifique que el neonato tenga derechos y, por el otro, no cuestiona la primacía de la autonomía sobre otros criterios posibles. No obstante, la argumentación basada en el potencial de autonomía como fuente de valor se debe sostener en otro principio, distinto al de la autonomía. Por ejemplo, se puede indicar que, sin mediar ninguna intervención que lo impida, el neonato se desarrollará en forma natural hasta transformarse en un ser autónomo.

Tal argumentación, como se indicó anteriormente, supone otorgarle valor moral a una característica del neonato (el ser un miembro de la especie humana). No obstante, como vimos en la sección 1, el ser un humano no es lo mismo que ser una "persona". Bajo el principio de autonomía es el ser persona lo que se constituye en fuente de derechos. Por lo tanto, limitar el infanticidio porque acaba con la vida de un potencial ser autónomo derrumba el edificio argumentativo basado en la autonomía para justificar el aborto porque no existe ninguna razón robusta para sugerir que dicho potencial existe sólo a partir del nacimiento (de hecho no es evidente que la autonomía biológica del feto se produzca recién al momento de nacer). No obstante, el punto que deseo remarcar es que el argumento es conceptualmente idéntico al que defienden los detractores de la despenalización del aborto. Por ejemplo, la variante católica (Juan Pablo II, 1995) de dicha crítica a la despenalización del aborto postula que el feto/embrión posee derechos porque tiene alma y aunque aún no es autónomo tiene el potencial de llegar a serlo. La fundamentación en base a tales potenciales es rechazada por los defensores de los derechos abortivos. No obstante, tal crítica se aplica por igual a su justificación de la prohibición del infanticidio sobre la base del potencial de autonomía del neonato. ¿Por qué la potencialidad puede ser justificación para tener derechos? Esa misma potencialidad es descartada para justificar el aborto (la madre es un ser autónomo, el embrión/feto no lo es), por eso, poseer "potencialidad de autonomía" sólo puede ser considerado fuente de derechos en virtud de algún principio distinto al de autonomía, por ejemplo, un principio metafísico que asuma la existencia de alguna esencia en el embrión, el feto o el neonato. Por ende, apelar a consideraciones biológicas derrumba el edificio argu- 
mentativo construido sobre el principio de la autonomía para justificar éticamente el aborto.

Por otro lado, una distinción entre aborto e infanticidio puede intentarse a partir de la justificación del actuar de la madre. Por ejemplo, puede argumentarse que al nacer ya no afecta a un tercero (la madre). Lamentablemente, ese argumento es incompleto. Si el único criterio de valor es la autonomía, ¿por qué tendría el recién nacido por el hecho de haber nacido derecho a seguir viviendo? El argumento aunque atractivo en apariencia nuevamente es falaz. El derecho de un ser autónomo para hacer lo que le plazca cuando no afecta a otro ser autónomo (como en este caso) se deriva directamente de la autonomía. Si no hay daño a terceros, la autonomía prima por sobre cualquier otra consideración. Por lo tanto, lo consistente con el principio de autonomía sería reflexionar en las siguientes líneas: no es que el neonato tenga derecho a la vida; es que dentro del útero afecta la autonomía de la madre y afuera no. Como aún no es un ser autónomo, carece de derechos. Matarlo sería, por ende, éticamente válido bajo el principio de autonomía. En consecuencia, debería aceptarse como éticamente legítimo que, si así lo desea, la madre acabe con la vida del recién nacido. Ello no sería éticamente cuestionable y correspondería preguntarse si se justifica que sea legalmente punible como, al igual que el aborto, lo es en nuestra legislación. Por ende, bajo el principio de autonomía, ni las motivaciones de la madre para matar al neonato pueden ser cuestionadas ni defensa alguna de los derechos de este último puede ser esgrimida al menos que dicha defensa se funde en un principio distinto al de la autonomía.

Entre las críticas y reacciones al artículo de Giubilini y Minerva (2012), una particularmente interesante es la presentada por el profesor Ezio Di Nucci. Di Nucci (2012) propone que Giubilini y Minerva (2012) y, por defecto, los autores que antes de ellos han indicado que el aborto y el infanticidio poseen el mismo status moral están equivocados porque el nacimiento es un hecho moralmente relevante.

Por un lado, sostiene Di Nucci, en el caso del aborto existe sólo un ser autónomo involucrado (la mujer embarazada) y, por ende, la decisión soberana sobre su cuerpo prima. Pero en el caso de un neonato aparecen otros seres autónomos (el padre, por ejemplo). Di Nucci sostiene que el punto central de la consideración de otros seres autónomos no es la distinción entre contextos donde el infanticidio podría ser permitido y contextos en los que no sería aceptable (por ejemplo, que sea 
aceptable en casos en que los padres estén de acuerdo y condenable en los casos en que no sea así). Su punto fundamental, indica, es remarcar que el status moral del nacido es distinto al del feto. Pero eso no es cierto. Si el principio rector es la autonomía, el recién nacido no adquiere, por el hecho de nacer, la condición de ser autónomo. Si no adquiere tal condición, entonces, el status moral del infante y del feto no ha variado. Lo que sí ha cambiado es el número de seres autónomos que podrían tener injerencia en la decisión sobre terminar o no con la vida tanto de un neonato como de un feto o embrión. Más aun, como el propio Di Nucci deja entrever, si el padre posee derechos sobre el neonato, cabe preguntarse si tales derechos no son extensibles respecto del feto. Posibilidad que de aceptarse pone en entredicho el derecho sobre el propio cuerpo de la madre, dice Di Nucci: "este argumento respecto de la asimetría moral entre fetos y neonatos [...] no depende de la ambigüedad del término 'fetos' con respecto a fetos en una etapa temprana o tardía (aunque uno puede imaginarse diciendo algo similar sobre el posible rol del padre con respecto a fetos viables en su fase final de desarrollo)" (traducción propia, Di Nucci 2012:5).

La segunda línea argumentativa propuesta por Di Nucci para distinguir entre el status moral del infanticidio y del aborto se funda en el valor moral del dolor. Argumenta Di Nucci que "sentir dolor" es una categoría moral relevante por sí misma. Esta línea argumentativa parece ser más prometedora que las anteriores para justificar el rechazo del infanticidio y permitir el aborto (al menos, durante el período en el que los sistemas neuronales que regulan el placer/dolor no han sido formados aún en el feto).

Ahora bien, es necesario remarcar que bajo el principio de autonomía - al menos en el sentido de Tooley y Warren y las extensiones lógicas de este argumento tratadas en la primera sección - no hay ningún impedimento ético para cometer infanticidio haya o no nacido sano el nuevo miembro de la especie humana y sufra o no. Si lo que otorga valor ético es el principio de autonomía, ¿por qué el sufrimiento de un recién nacido no autónomo es criterio moral relevante? El que tenga dolor no es en sí mismo fuente de valor moral bajo el principio de autonomía. Sólo puede tener importancia si el dolor refiere a "otra fuente" de valor. Nuevamente, ante esta nueva fuente de valor, cabe preguntarse ¿por qué sorpresivamente adquiere importancia recién cuando el individuo nace? Pero más importante aún, apelar a otro principio ético de 
carácter no-metafísico para justificar el aborto (pero rechazar el infanticidio) obliga al defensor de la suficiencia ética del principio de autonomía a, por lo menos, plantear una jerarquización normativa. El principio de autonomía debe cumplirse primero, y el principio del "dolor/placer" después.

Ésa es una jerarquización válida en muchos contextos. Por ejemplo, supongamos que a un esclavo le gusta su condición de tal, ¿es ésa una razón suficiente para que la esclavitud sea legítima? Bajo un orden lexicográfico normativo fundado en la autonomía la respuesta es clara: no, porque la autonomía prima. Es decir, el esclavo tiene derecho a la autodeterminación y ese principio se superpone sobre el placer que, hipotéticamente, pueda sentir en su condición de sumisión. Siendo este análisis correcto para condenar y rechazar la esclavitud, no es un análisis correcto en el tema del aborto. En el primero, la autonomía del esclavo no está bajo sospecha: se trata de la relación verificable entre dos individuos autónomos, uno de los cuales está sometido a los designios del otro. En tal circunstancia, la renuncia a la autodeterminación en la búsqueda del beneficio utilitario del placer invierte de forma injustificable la jerarquía de principios morales que une a la autonomía y la satisfacción como fuentes de valor (más sobre el punto, adelante).

En el caso aquí estudiado, el embrión, feto o recién nacido no son autónomos. ¿Cómo entonces sus dolores pueden ser fuente de valor si aún no son seres autónomos? Sólo invirtiendo el orden (dolor/placer primero, autonomía después) podría ser justificable que no se termine con la vida de un recién nacido. Eso tiene dos implicancias. Primero, si ello es válido para un recién nacido, vuelve a surgir la pregunta sobre por qué no lo es dentro del útero materno. Para Di Nucci (2012), si se acepta que un ser tiene derecho a que no se le cause dolor, los neonatos $\mathrm{y}$, posiblemente, los fetos en sus últimas etapas de desarrollo tienen derecho a no ser eliminados. A su juicio, ése es un argumento que no sería controversial entre muchos partidarios del aborto, especialmente entre quienes limitan la legitimidad del mismo a los primeros meses de embarazo. Segundo, al apelar a otro criterio de valor para rechazar el infanticidio la supremacía del principio de autonomía debe ser abandonada. Sólo una relajación del supuesto de la supremacía de la autonomía por sobre el dolor/placer puede hacer consistente condenar el infanticidio de un nacido sano (y quizás, el de abortos de fetos en sus etapas finales de desarrollo). Pero al hacerlo, la fortaleza argumentativa para justificar el 
aborto basándose en la exclusividad de la autonomía debe ponerse entre paréntesis.

Por último, existen dos problemas más elementales en la argumentación basada en el concepto de dolor/placer. El primero está relacionado con la inconmensurabilidad del dolor de uno versus el bienestar de otro. Cabe preguntarse si las reacciones físico-biológicas de un ser no autónomo, por ende, que no posee conciencia de sí mismo, son, éticamente hablando, equiparables a lo que se entiende como placer y dolor en seres autónomos. Tal discusión escapa a los fines de este artículo, no obstante su análisis es similar al que hace Tooley (1974) para distinguir entre ser humano como descripción de un miembro de la especie homo sapiens y ser humano como persona autónoma. El segundo problema, dice relación con la razonabilidad del placer/dolor como fuente de valor en un ser no autónomo. Si no existe un ser autónomo consciente de sí, ¿qué sentido tiene argumentar que tal ser posee derechos a que no se le cause dolor? Mi inclinación es a pensar que la dimensión dolor/ placer sólo adquiere valor ético en el marco que genera el principio de autonomía. Vale decir, porque son conscientes de sí mismos, seres autónomos pueden dar significado a experiencias identificables como placer o dolor, no así seres que carecen de tal condición.

En suma, una argumentación que afirme que existe una diferencia en el status moral de un neonato y un feto debe sostenerse sobre algún principio distinto a la autonomía. Pero si tal argumentación es considerada válida, necesariamente contradice dicho principio y puede, por ejemplo, justificar restricciones sobre el derecho de la mujer embarazada sobre su propio cuerpo. La única forma de evitar que ello suceda es aceptando que el infanticidio es éticamente compatible con el principio de autonomía. Posibilidad que, como vimos, no resulta razonable.

\subsection{La defensa agnóstica de la distinción entre feto y neonato}

En los dos puntos anteriores se han revisado argumentos que podrían ser esgrimidos para generar una distinción moral entre aborto e infanticidio. Si el análisis realizado es correcto, ninguno logra su objetivo. Un aspecto común a todos ellos es que intentan simultáneamente justificar el aborto y rechazar el infanticidio sobre la base de una distinción moral del feto y el neonato. Torcello (2009) ofrece una reflexión alternativa en la que tal distinción está ausente, pero que — de ser correc- 
ta - ofrece una justificación del aborto y un rechazo del infanticidio. Torcello parte afirmando su escepticismo respecto a la posibilidad de distinguir cuál es el status moral del feto y, sobre esa base, se pregunta cómo una sociedad de individuos autónomos y racionales procedería para definir las reglas de convivencia en esta materia.

Torcello sostiene que la incertidumbre sobre el status moral del feto debe asumirse como un dato y para emitir un juicio ético debe primero aceptarse un principio precautorio que consiste en que, en situaciones donde no existe certeza sobre el status moral de una acción, se debe dar a la acción el beneficio de la duda y tolerarla. Dice Torcello: "Si una sociedad sostiene como punto de partida la razonable posición que las mujeres son ciudadanos de innegable relevancia moral, entonces cualquier limitación al derecho de la mujer a abortar en cualquier etapa de su embarazo debe ir acompañada por una fuerte razón pública" (Torcello 2009:24). Entonces, al no existir certeza sobre el status moral del feto, la imposición de límites en los derechos de un ser autónomo (la mujer embarazada) no es justificable. En otras palabras, el principio liberal por defecto en ese escenario, indica Torcello, debe ser permitir - sin restricciones - que la mujer decida en cualquier etapa de su embarazo qué desea hacer sobre él. Al contrario, indica el autor, una vez nacido, la misma duda razonable sobre el status moral del ahora neonato persiste, pero aquella incertidumbre no debe ser evaluada ni comparada con el derecho de ningún otro ser autónomo; por ende, concluye Torcello, el principio precautorio aconseja en este caso preservar la vida del recién nacido.

Aparentemente, el argumento logra limitar el alcance del principio de autonomía denegando la validez ética del infanticidio sin tener que acudir a otro principio distinto. Existen razones para afirmar que el argumento no logra ser coherente con una noción de razón pública propia del liberalismo político cuyo análisis escapa a los objetivos de este artículo (para una crítica sobre este punto véase Friberg-Fernros 2010:31-35). Para el propósito planteado aquí, en torno al análisis de la coherencia de una argumentación ética, el problema del postulado de Torcello (2009) es aún más básico: el hecho que no exista un acuerdo en torno al status moral del feto no se debe a que se ignore cuál es el "verdadero" status moral que posee, como sugiere el autor, sino a la existencia de criterios axiomáticos diferentes sobre los cuales basar el juicio normativo. Torcello confunde incertidumbre con desacuerdo. Bajo la 
primacía de la autonomía tal incertidumbre no existe. Como tampoco existiría si se postula el argumento metafísico según el cual el derecho a la vida se obtiene por el hecho de pertenecer a la especie humana. No obstante, Torcello intenta transformar una discrepancia axiomática en una incertidumbre, para luego tomar una posición escéptica y aplicar el principio precautorio.

Para justificar la decisión de fundar su juicio moral sobre una mirada escéptica, Torcello cita a Russell: “(1) [...] cuando los expertos están de acuerdo, la opinión opuesta no puede ser tomada como cierta; (2) Cuando ellos no están de acuerdo, no existe una opinión que pueda postularse como cierta por los no-expertos y (3) cuando ellos coinciden que no existe terreno para una opinión positiva, el hombre común haría bien en suspender su juicio [...]" y agrega "es simple aplicar este argumento al aborto. Los 'expertos', esos profesionales de la ética que escriben sobre la materia, están lejos de tener un acuerdo. Hay de hecho una vasta literatura que muestra cómo personas racionales de forma coherente y persistente discrepan en el tópico del aborto. Los temas esenciales sobre el aborto siguen sin ser resueltos y hay buenas razones para asumir que ellos seguirán sin resolverse [...]". Finalmente, concluye que debido a que no puede haber certezas sobre el status moral del feto, "entonces, ceteris paribus uno debe resistirse de imponer cualquier restricción legal a la libertad de elección de la mujer. Eso es consistente con el argumento de Russell" (cursivas en el original, traducción propia, Torcello 2009:20-21).

El problema es que la condición de expertos de los estudiosos de la ética dice relación con su capacidad de someter principios éticos a escrutinio, estudiar sus consistencias internas y derivar sus implicancias, pero en ningún caso refiere a una condición especial de éstos respecto al conocimiento sobre el valor normativo de dichos principios morales. En consecuencia, su discrepancia no se funda en una incertidumbre que debe ser o, potencialmente, podría ser esclarecida con mejores técnicas o más información ${ }^{5}$. Su discrepancia es el resultado de evaluar un mismo fenómeno desde principios éticos diferentes.

${ }^{5}$ Sí estaríamos frente a una incertidumbre si, asumiendo el principio de autonomía como válido, deseamos definir desde cuándo exactamente un ser humano adquiere tal status. En ese caso, si es factible postular que existen expertos (no eticistas, sino biólogos y médicos) que poseen un conocimiento más acabado y que si ellos no están de acuerdo sobre cuál es dicho momento, el resto de la población debe suspender su propio juicio y aplicar el principio precautorio. 
En ese plano, una metodología que intente dirimir cuál de esos principios (si es que existe alguno) es más razonable como fundamento de valor no puede basarse en un escepticismo sobre principios éticos. Por el contrario, debe analizar las implicancias de cada uno y evaluar su razonabilidad. Por lo demás, tal escepticismo en la argumentación de Torcello no es tal, toda vez que uno de los principios éticos que aspiran a dirimir los dilemas éticos en torno al aborto (el principio de autonomía de la mujer) es asumido como válido de entrada. Por ello, la conclusión a la que llega Torcello está predefinida en el método seleccionado: cuando el punto de partida es que la mujer tiene derechos sobre su cuerpo por ser un ser autónomo y un manto de incertidumbre es puesto sobre cualquier otro principio que pueda postularse para limitar ese derecho (en virtud de otorgar status moral al feto), se puede esperar que el resultado del ejercicio analítico culminará en una reafirmación de tal derecho de la mujer. En suma, el método propuesto no logra su pretensión de ser neutral respecto a los distintos postulados sobre el status moral del feto y los derechos reproductivos de la mujer; inclinando $a$ priori la balanza hacia el último. No obstante, como vimos en nuestro análisis del argumento de Thomson (1974), precisamente aquello que se ignora es el punto en discusión al debatir sobre el aborto. Nada éticamente relevante acontece con el nacimiento tanto si se postula que el principio rector es el de la autonomía como si se plantea que el feto tiene derecho a la vida en cuanto miembro de la especie homo sapiens. En ambos casos existe un juicio moral consistente respecto al aborto (aunque contrapuestos el uno con el otro) y, en el caso particular que se analiza en este documento (la autonomía), obliga a concluir a favor de la justificación ética del infanticidio.

\subsection{Autonomía e infanticidio}

En las tres secciones anteriores, se han revisado algunas de las principales argumentaciones existentes en la literatura que, sobre la base del principio de autonomía, justifican el aborto y rechazan el infanticidio. Si el análisis anterior es razonable, toda argumentación sobre el aborto que se funde en el principio de la autonomía debe concluir que, debido a que ésta sólo se verifica semanas o quizás meses después del nacimiento, cualquier interrupción de la vida antes de ese momento sería éticamente incuestionable. En consecuencia, el postulado ético que 
sostiene que, basado en el principio de autonomía, nadie en la sociedad puede legítimamente intervenir sobre los derechos reproductivos de la madre debe también postular como éticamente válido que esos derechos se extiendan hacia la aceptación del infanticidio de un neonato en todas sus formas.

Lo anterior no significa que existan contradicciones lógicas en el principio de autonomía que lo invaliden como fundamento ético en estas materias. El criterio es consistente internamente. El asunto es que posee implicaciones más allá del aborto que pueden llevar a muchos lectores ante una disyuntiva, como bien anticipara Warren, porque tales consecuencias serían (en sus palabras) monstruosas (ver penúltimo párrafo en la sección 1). Existen buenas razones para pensar que en la actualidad, el rechazo al infanticidio como práctica crece, y que tal avance no obedece a dogmas religiosos sino que al redescubrimiento en las sociedades contemporáneas del valor simbólico de lo humano como algo que posee valor independientemente del principio de autonomía. Tal redescubrimiento se tornaría evidente en la carga emocional con la que se recibe y protege al recién nacido. En tal contexto, la insistencia de la exclusividad del principio de autonomía como fundamento ético para reflexionar sobre el aborto sólo puede interpretarse como un dogma.

\section{3. ¿La primacía de la autonomía?}

La reflexión en torno al principio de autonomía, como ante todo criterio moral, tiene un origen histórico y, como tal, es contingente. No obstante, la lógica impecable que de él se deriva para hablar de los problemas de la vida en común entre seres cuya condición de autonomía es evidente, justifica que en muchas situaciones se ignore, sin problemas, tanto su origen histórico como sus limitaciones. Por ejemplo, a la hora de reflexionar sobre el valor de la libertad de expresión, o el de la autodeterminación de los pueblos, o al rechazar cualquier pretensión de legitimidad de la esclavitud, o al discutir sobre la libertad de las personas para decidir con quién unirse en matrimonio, en cada uno de esos casos los individuos involucrados son todos autónomos o es razonable asumir que poseen tal condición. Es autónomo quien expresa sus opiniones; son autónomos los ciudadanos de una nación que están decidiendo sobre cómo elegir sus representantes; autónomos son tanto el esclavo como su dueño y lo mismo acontece con los que están deci- 
diendo si quieren compartir su vida en vínculo matrimonial sea cual sea su género. En todos esos casos, como la autonomía de los involucrados es evidente, el hecho de asumir el principio de autonomía para construir reflexiones éticas desde él es apropiado. Ninguna legislación que limite los derechos a la autodeterminación en esos contextos puede considerarse éticamente justificable: no lo sería el impedir que una persona exprese sus opiniones; tampoco sería éticamente aceptable que una nación deba obediencia a un individuo o grupo de individuos que ellos no hayan elegido; como se indicó anteriormente, ni siquiera si la persona lo desea, podría permitirse que sea esclava de otra; y, por último, la legislación no tendría derecho de prohibir el matrimonio entre personas adultas sean o no de distinto género.

Muchos otros ejemplos pueden ser considerados para demostrar el poder rector que el principio de autonomía posee en múltiples escenarios para resolver nuestros dilemas éticos. Por ello, es comprensible que algunas personas tengan una inclinación hacia concluir que la autonomía es un criterio no sólo necesario sino también suficiente en todas las circunstancias. Otras fuentes éticas carecen de esa pretensión de universalidad. Por ejemplo, las éticas basadas en creencias religiosas dependen de que tales creencias sean compartidas por los que se sometan a las regulaciones que dichas creencias establecen. Las éticas basadas en el placer/dolor (el utilitarismo, por ejemplo) se ven entrampadas en problemas éticos de difícil solución en aquellas circunstancias donde el placer de unos implica el dolor de otros. El principio de autonomía no se enfrenta tan fácilmente a limitaciones en su aplicabilidad como dichas alternativas. No obstante, en algunos temas contemporáneamente relevantes como el aborto, el principio de autonomía se enfrenta a sus propios límites. A mi juicio, dilemas similares existen respecto a su aplicabilidad en discusiones ecológicas. Por ejemplo, en los dilemas éticos derivados de la decisión de limitar o no la autonomía de una generación de humanos en la explotación de recursos naturales en virtud de la justicia respecto a las generaciones futuras.

Ante estas limitantes existen dos posibles reacciones. La primera es ignorar que todo criterio ético con pretensión de universalidad debe demostrar caso a caso su supremacía sobre otros criterios. Es decir, actuar dogmáticamente, afirmando que el criterio de autonomía "es" universal, incuestionable, fundacional. Tal camino tiene por desenlace la adopción de una postura que sólo puede ser sostenible mediante coac- 
ción política sobre aquellos que no comparten tal doctrina y, por ende, no puede formar parte de la razón pública. Como tal, ese camino no es consistente con el liberalismo político.

La segunda es intentar entender qué especificidades poseen los temas del aborto o la sustentabilidad medioambiental que podrían imponer restricciones a la aplicación del principio de autonomía. En esta segunda línea, es mi impresión que las limitaciones se derivan de la definición misma del concepto. Autonomía o autogobierno o autodeterminación es un estado constatable pero no determinable. Es decir, al parecer, no existe un momento tal en el desarrollo de un ser humano que pueda identificarse con claridad para decir que antes de ese instante el individuo no es un ser autónomo y después de él sí lo es. Las dificultades que esta ambigüedad genera son evidentes: bajo el principio de autonomía, una acción que puede ser éticamente aceptable (acabar con la vida de un ser no-autónomo) puede dejar de serlo un instante después. Como consecuencia, el mero paso del tiempo adquiere valor moral. En consecuencia, el concepto de autonomía se enfrenta a sus propios límites cuando se torna forzoso poseer una definición clara sobre su inicio. ¿Por qué sucede esto? Cuando, por ejemplo, Kant y sus contemporáneos reflexionaban sobre estas materias y el filósofo en su Metafisica de las Costumbres expresa el principio de la autonomía con claridad, el tipo de problemas que inquietaba no incluía el escenario en el que un ser no autónomo puede evolucionar hasta llegar a serlo. Las preocupaciones de la autonomía versus la heteronomía versaban todas sobre temas de la vida en común entre adultos cuya autonomía no estaba en discusión. Lo que se estaba gestando eran los principios éticos del autogobierno de los pueblos y la justificación ética de los derechos individuales. En esas circunstancias, sólo el rechazo del poderoso podía explicar que se privara a una persona de seguir su propia legislación interna. En esos casos, la argumentación sobre la base de la autonomía es impecable. El sometimiento a la ley creada por otros sólo puede justificarse si se funda en imperativos éticos que emergen del respeto de la voluntad individual. No obstante, en ninguna de las circunstancias que les inquietaba a los pensadores de la época, la existencia de la autonomía de los involucrados podía ponerse en duda. El individuo sometido al yugo de otro, el esclavo por ejemplo, no está libre, pero es un ser autónomo. Su condición de ser autónomo no está puesta en duda. 
En los tiempos presentes, donde surgen otras preocupaciones que eran impensadas antaño, existe la tentación de creer que, debido a que la argumentación desde la autonomía es válida en muchos contextos, debe ser usada en este contexto sin necesidad de justificación. No obstante, la pretensión de que estamos ante un argumento de mayor grado de validez simplemente porque el argumento es poderoso y ampliamente aceptado en múltiples asuntos tiene ribetes dogmáticos. A nada controversial (es decir, a ningún dilema ético) nos enfrenta el concepto "autonomía" cuando las personas pueden consensuar escenarios donde se aplica. Pero allí donde no hay consenso, todas las limitaciones del concepto se revelan y su capacidad orientadora del juicio moral queda entre paréntesis.

Al reflexionarse en torno al aborto y al infanticidio se torna necesario delimitar con claridad desde cuándo opera el concepto de autonomía, pero el intento de proveer tal claridad parece ser poco prometedor. Sólo si cometemos la falacia de la composición podríamos ignorar que es perfectamente posible que el criterio de la autonomía sea simultáneamente válido en una dimensión y tener problemas para iluminarnos en otra.

A partir de las reflexiones anteriores cabe preguntarse si es posible asumir la primacía de la autonomía como concepto para hablar del aborto. A mi juicio, la respuesta es que ello sólo puede hacerse aceptando las implicancias (contemporáneamente indeseables) que justifican éticamente el infanticidio $\mathrm{y}$, por ende (contra los tiempos) abriendo espacio a la justificación ética del uso instrumental de la vida de todo humano cuya condición de autonomía no sea verificable. Enfrentados a tal posibilidad parece razonable concluir que los propios individuos autónomos justificarán la imposición de límites en pos de proteger la vida del recién nacido. Tal decisión sólo puede fundamentarse en fuentes de valor distintas al principio de autonomía.

Ello no significa que el principio normativo de la autonomía pierda importancia, sino que su valor debe ser sopesado con otras posibles fuentes de criterios éticos. Para quienes nos sentimos inclinados a pensar acerca de lo justo en diversas materias sobre la base del principio de autonomía, las dificultades que aquí se retratan radican en la indeterminación que existe sobre aquel momento en el que el ser vivo que no es sujeto de derecho (porque no es autónomo) pasa a ser sujeto de dere- 
cho ${ }^{6}$ ¿ ¿Por qué un principio que nos remite a reflexionar sobre una etapa del desarrollo humano donde el principio no es verificable ha de ser el principio sobre el cual basar nuestras conclusiones éticas en estas materias? Tal pretensión no se sostiene por sí misma. Las mismas críticas que con justa razón los defensores de la autonomía sostienen frente a los que postulan razones religiosas para rechazar la despenalización del aborto caen sobre ellos y con la misma fuerza cuando tal dogma quiere ser impuesto. En definitiva, los dilemas éticos a los que nos expone la legalidad/no legalidad del aborto obligan a quien funda su inserción en el mundo sobre principios liberales a reconocer que, en base a esos mismos principios y sólo en base a ellos, no es posible dirimir el dilema ético del aborto.

La nuestra es una época hija del principio de autonomía. A él debemos, sin exagerar, la legitimidad de todas o casi todas nuestras libertades. Los tiempos corren de tal forma que la autonomía gana mayorías y penetra profundamente en el sentir y actuar de la población. El espacio para la aplicación dogmática de los principios normativos y orientadores del principio de autonomía se acrecientan. He ahí el riesgo para una sociedad fundada sobre esos principios. Como indicara Dewey (1927), el poder que otorga el ser mayoría es vacío por sí mismo. Su valor descansa, en último término, en los métodos y condiciones de debate, discusión y persuasión que le precedieron. A la luz del valor que en las sociedades contemporáneas crecientemente se le da a la protección de la vida del infante, tales debates parecen sugerir que lo razonable es reconocer limitaciones a la aplicación del concepto de autonomía en el tema del aborto. En suma, el redescubrimiento de lo humano como un valor a proteger incluso en homo sapiens no autónomos como los recién nacidos (que parece profundizarse en los tiempos actuales) sugiere revi-

${ }^{6}$ Nótese que la incertidumbre en este punto no es del mismo tipo que la postulada por Torcello. Como sostengo en la sección 2.3, la incertidumbre a la que se refiere Torcello no es en realidad una incertidumbre. Ella más bien refiere a la selección de distintos criterios axiomáticos sobre los cuales fundar la reflexión ética. Aquí, en cambio, la incertidumbre sí es tal y se refiere a que, una vez seleccionado el principio de autonomía como el criterio sobre el cual fundar el juicio ético, no existe un instante en el desarrollo del individuo que pueda sostenerse sin ambigüedades como aquel momento en que la autonomía comienza a operar (aunque sí puede decirse que acontece después del nacimiento). Agradezco al árbitro anónimo de Estudios Púlbicos que llamó la atención sobre este punto. 
sar el silogismo de Warren comentado en la sección 1. Son los propios individuos autónomos los que, desprovistos de dogmas religiosos y reconociéndose como individuos libres e iguales, atribuyen a un recién nacido derechos en cuanto ser biológico y miembro de la misma especie. En consecuencia, la pregunta moral es nuevamente puesta sobre la palestra: ¿cuándo un ser humano adquiere el status moral de sujeto de derechos? Enfrentados a reconocer las consecuencias de responder a esa pregunta con un "desde que son autónomos", son los propios seres autónomos los que elevan a un status moral criterios que originalmente descartaban como inválidos. Abierta tal compuerta, la justificación ética de los derechos abortivos es nuevamente puesta entre paréntesis.

\section{REFERENCIAS}

Bascuñán, Antonio. "La Licitud del Aborto Consentido en el Derecho Chileno". Revista de Derecho y Humanidades, ํ10 (2004), pp. 143-181.

Becker, Gary. A Treatise on the Family. Harvard University Press, 1993.

Dewey, John. The Public and Its Problems. New York: H. Holt and Company.

Di Nucci, Ezio. "Killing Fetuses and Killing Newborns". 2012 (accedido el 10/03/ 2012 en http://papers.ssrn.com/sol3/papers.cfm?abstract id=2016772)

Juan Pablo II. "Evangelium Vitae. On the Value and Inviolability of Human Life". Encyclical Letter, 1995.

Friberg-Fernros, Henrik. "Abortion and the Limits of Political Liberalism". Public Reason Vol. 2, № 1 (2010) pp. 27-42.

Giubilini, Alberto, Francesca Minerva. "After-birth Abortion. Why Should the Baby Live?" Journal of Medical Ethics, 2012 doi:10.1136/ medethics-2011-100411.

Rawls, John. Political Liberalism. Columbia University Press, 1993.

Rothbard, Murray. The Ethics of Liberty. New York University Press, 1998.

Singer, Peter. Ética Práctica. Ediciones AKAL S.A, 2009.

Thomson, Judith J. "Una Defensa del Aborto". En Debate sobre el Aborto. Cinco Ensayos de Filosofía Moral. Editorial Cátedra, 1974, pp. 9-32.

Tooley, Michael. "Abortion and Infanticide". Philosophy and Public Affairs Vol. 2, $\mathrm{N}^{\circ} 1$ (1972) pp. 1-12.

_Aborto e Infanticidio". En Debate sobre el Aborto. Cinco Ensayos de Filosofía Moral. Editorial Cátedra, 1974, pp. 69-107.

Torcello, Lawrence. "A Precautionary Tale: Separating the Infant form the Fetus". Res Publica, N 15 (2009), pp. 17-31.

Warren, Mary Ann. "On the Moral and Legal Status of Abortion". The Monist, Vol. 57, $\mathrm{N}^{\circ} 4$ (1973). Parte II reimpresa.

Zelizer, Vivian. "The Price and Values of Children: The Case of Children Insurance”. Journal of Sociology Vol. 86, № 5 (1985), pp. 1036-1056. 